\title{
The Domain of Challenges and Coping Mechanisms Amongst Caregivers of Autistic Children
}

Khairunnisa Zainal, Siti Marziah Zakaria, \& Nur Saadah Muhammad Aun

To Link this Article: http://dx.doi.org/10.6007/IJARBSS/v11-i6/10225

DOI:10.6007/IJARBSS/v11-i6/10225

Received: 16 April 2021, Revised: 18 May 2021, Accepted: 29 May 2021

Published Online: 19 June 2021

In-Text Citation: (Zainal et al., 2021)

To Cite this Article: Zainal, K., Zakaria, S. M., \& Aun, N. S. M. (2021). The Domain of Challenges and Coping Mechanisms Amongst Caregivers of Autistic Children. International Journal of Academic Research in Business and Social Sciences, 11(6), 946-957.

Copyright: (c) 2021 The Author(s)

Published by Human Resource Management Academic Research Society (www.hrmars.com)

This article is published under the Creative Commons Attribution (CC BY 4.0) license. Anyone may reproduce, distribute, translate and create derivative works of this article (for both commercial and non-commercial purposes), subject to full attribution to the original publication and authors. The full terms of this license may be seen at: http://creativecommons.org/licences/by/4.0/legalcode

Vol. 11, No. 6, 2021, Pg. 946- 957

http://hrmars.com/index.php/pages/detail/IJARBSS

Full Terms \& Conditions of access and use can be found at http://hrmars.com/index.php/pages/detail/publication-ethics 


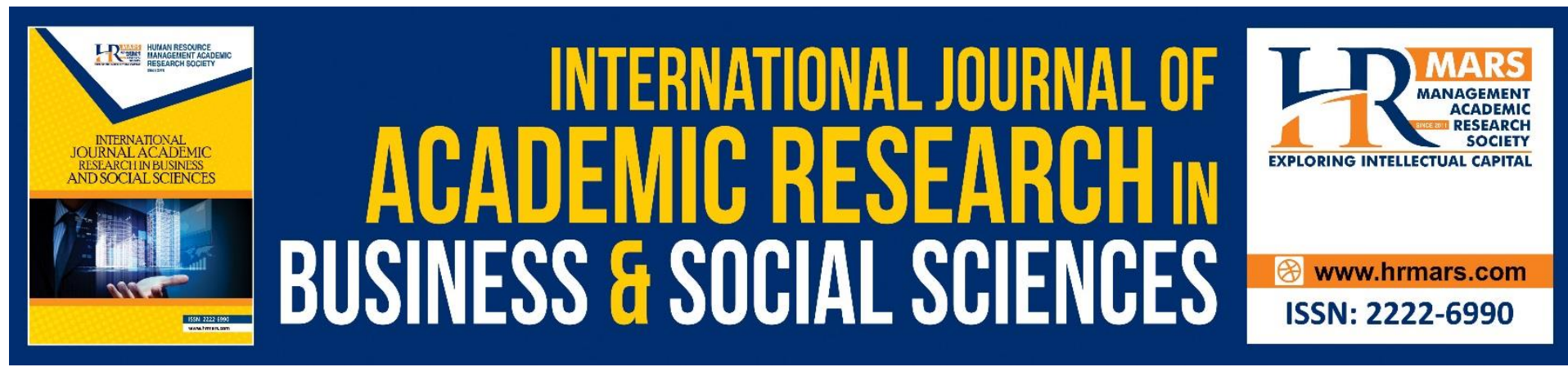

\title{
The Domain of Challenges and Coping Mechanisms Amongst Caregivers of Autistic Children
}

\author{
Khairunnisa Zainal, Siti Marziah Zakaria, \& Nur Saadah \\ Muhammad Aun \\ Center for Research in Psychology and Human Well-Being, Faculty of Social Science and \\ Humanities, The National University of Malaysia, 43600 Bangi, Selangor, Malaysia \\ Email:marziah@ukm.edu.my
}

\begin{abstract}
Autism spectrum disorder present challenges, stress, and burdens to caregivers. In order to ensure the quality of life especially the well-being of caregivers, they need necessary supports. This study uses a qualitative method which is in-depth interviews to explore the domains of caregivers' burden and challenges as well as their coping mechanisms. This study has been conducted among caregivers registered with NASOM Melaka. A total of 8 respondents participated in this study voluntarily, consisting of 7 women and a man. The data was collected via a series of online interviews. The analysis was conducted based on thematic analysis. Financial, emotional, physical, and social life challenges are the domains contributing to the burden of caregiving. The financial issue is reported to be the most important challenge in caregiving. This is due to the high costs involved in the management of treatment and therapy, as well as the cost of food and daily expenses. Acceptance and spiritual aspects are the positive coping mechanisms for the management and caregiving of autistic children. In conclusion, caregivers also need emotional and practical supports from family members. Government and Non-Governmental Organisations should be more attentive to the need and constraints faced by the caregivers, especially financial constraint.
\end{abstract}

Keywords: Autism Spectrum Disorders, Caregiver Stress, Well-Being, Psychological WellBeing, Coping Mechanism.

\section{Introduction}

Autism Spectrum Disorder (ASD) is one of the groups categorized as disabled under the category of learning disabilities (Department of Social Welfare, 2019). According to Nik Aida et al. (2019), autism is a neurological disorder characterized by deficits in the aspects of social interaction, social communication, and behavior. A study by APA (2013) found that this disorder is often comorbid with problems such as intellectual disability, motor coordination problems, attention disorders, epilepsy, aggressiveness, eating disorder, and sleeping issues. However, the autistic characteristics of individuals categorized as ASD are still difficult to be treated due to the complexity of the condition. Given the nature of this disorder, caregiving autistic children is inevitably more challenging than caregiving normal children. In this regard, 
the challenges experienced by working parents and caregivers themselves are related to their own well-being and the quality of care for autistic children. Caregiver of autistic children need to handle and endure a complex characteristics and behaviours of the child. Bashir et al. (2014) agreed that raising children with autism is a very challenging experience for parents and the whole family members. The statistics of people with autism spectrum disorder (ASD) are on the increase continuously. Li et al (2019) stated that Autism Spectrum disorder is one of the developmental disorders existing and now growing rapidly across the country. In Malaysia, local epidemiological studies on the prevalence of Autism spectrum disorder are yet to be available (MaHTAS, 2014). According to the Family Health Division, Ministry of Health (2016), the prevalence rate of autistic children in Malaysia is estimated at 1.6 in 1000 people, while in the United States of America the prevalence rate among children is generally estimated at around 14.7 per 1000, which is 1 out of 68 children aged 8 years (CDC, 2014). In addition, most individuals with this disorder are boys rather than girls (Karaarslan \& Kully, 2015).

\section{Literature Review}

The diversity of different spectrums and behaviours pose different challenges to caregivers in raising an autistic child. Recent studies have shown that various sources lead to the burden of caregivers in childcare especially in their early experience of diagnosis and challenges in family development (Topen et al., 2019). Zarit et. al (1980) define the burden as a condition that occurs because of the necessary care duties or restrictions that cause discomfort for a caregiver. Many previous studies have reported that most caregivers experience high levels of burden (Oh, Kyoung, \& Lee, 2009) mainly due to financial, social, psychosocial, cost of treatment, and transportation (Yamaoko et al., 2015; Sazlinan et al., 2018; Aida et al., 2019).

Caregivers of autistic children also reported many negative effects and lower aspects of psychological well-being. Similarly, a study conducted by Landon, Shepherd, and Goedele (2017) also states that parents of autistic children often experience dissatisfaction with their quality of life. Furthermore, some caregivers also experience the emotional burden of care which indirectly causing the decline in quality of life in many aspects (Chan and Lam, 2017; Ting et al., 2018; Broady et al., 2018; Wong et al., 2019). All individuals need a certain standard in the quality of life or well-being of life to achieve an acceptable level of life and psychological satisfaction. According to Azizah, Jamal and Roslina (2014), well-being is a dynamic process and human beings can give value to the growth of lives, either in a better direction or vice versa. Well-being is a very subjective issue because it refers to the experience of an individual who evaluates life through two different components, in terms of cognitive and affective (Diener, 1984; Diener et al., 1995).

Werner and Shulman (2013) state that most caregivers experience a decline in psychological well-being. According to Parameswari and Jeryda Gnanjne Eljo (2012), this is due to the diversity of responsibilities that need to be resolved especially in the management of individuals with disabilities. Hoefman et al. (2014) suggested that when caregivers are highly stressed out, family functioning decreases. This will translate into a decrease in the quality of life.

Although the burden experienced by the caregivers is reported to be increasing, there are not many studies that classify the type of burden experienced clearly and in detail, especially how 
the caregiver experiences the tension and the type of different burdens during various stages of the child development. The burden and stressful situation experienced by caregivers of autistic children is considered very important in determining the quality of life, family functioning, and well-being. Burden amongst guardians is a powerful predictor in determining psychological well-being (Cramm \& Nieboer, 2011). Therefore, in managing daily life, the wellbeing aspect plays an important role in a person's quality of life along with the existing surrounding environment to build a more meaningful life. Thus, this study is conducted to explore the burden and challenges in caregiving and their coping mechanisms to cope with the challenges in order to attain psychological well-being.

\section{Methodology \\ Research design}

In this study, the researchers have used qualitative design by adopting a phenomenological approach to explore the experience of informal caregivers who have children with Autism. The researchers have collaborated with The National Autism Society of Malaysia (NASOM) Melaka to approach the respondents. In the list of names received, there were a total of 22 prospect respondents and only 8 respondents voluntarily participated in this study and agreed to be interviewed. In this study, the researchers used a purposeful sampling technique aimed at obtaining respondents that meet the original purpose of the study. Following that, the researcher has set some parameters or conditions that needed to be met by the respondents:
a. respondents must be an individual caring for or a family member who cares for autistic children.
b. respondents aged between 25 to 60 years old; and
c. able to understand and speak either Malay or English.

\section{Research Instruments}

For this study, the researchers have developed a set of semi-structured questions to be used in interviews with the respondents based on the issues specified. The set of questions consisted of 3 parts:

a. Section A - demographics. In this section, the researchers presented questions of the study and explore the background of the respondent as well as the history of life;

b. Section B - experience as a caregiver. In this section, the researchers explored the experience as a caregiver, touching on aspects of burden;

c. Part C - coping mechanism and well-being. In this section, the researchers explored and delved into what factors contributed to the burden and its impact on the well-being of the caregiver.

\section{Research Ethics}

Before the study was conducted, the researchers first obtained the consent of NASOM's supervisor. After that, the researchers approached the names given using the WhatsApp application. Following the agreements to be interviewed, the researchers conducted online interviews. During the interview, the researchers first gave a brief explanation to the respondents on the purpose of the study. Researchers also informed them of guaranteed confidentiality. This is due to the fact that in qualitative studies, the oral protocol is a very 
important aspect that researchers need to adhere to (Othman, 2014). Hence, the researchers developed an oral protocol to obtain information based on the purpose of the study.

\section{Research Analysis}

The researchers chose to use thematic analysis techniques to analyse the issues studied. The thematic analysis is an analysis that can be used to extract patterns or themes related to specific issues. This thematic analysis is also a flexible basic analysis for researchers in conducting data analysis (Braun and Clarke, 2014).

\section{Result of the Study}

Demographic Background of Respondents

Descriptive analysis was used in explaining the demographic profile information of the respondents. In general, in this study, a total of 22 parents or guardians were included in the list given by NASOM to be the possible participants. Out of that, only 8 were willing to participate in the online interview conducted by the researchers. All of them have autistic children ranging from 8 to 22 years old. The respondents in this study were all parents or guardians who sent their children to the NASOM Care Center, Melaka. Table 1 shows the demographic summary of the study respondents, while Table 2 shows the demographic summary of the respondents' children categorised as autistic. To maintain the confidentiality of the respondents, the researchers labelled each respondent with identification codes namely R1, R2, R3, R4, R5, R6, R7, and R8, with pseudonyms (false name).

Each aspect in this demographic section gives its own importance to everyone. Results of the study will be provided by the background of the respondents where important information such as the number of children in the family, the autism category, and its severity, and sociodemography of caregivers. This is because each of this information is individualised and provides a different effect to the respondent in the management of the specialised childcare. The position of the child among the siblings and the number of children also touches the aspect of child growth and contribute to the burden of caregivers of the children. Most of the respondents informed that the other children greatly assisted in caregiving, even at a young age. Hence, their assistance indirectly impacted the social growth of autistic children to interact even though the main characteristics of autism remained unchanged. There were eight (8) respondents who voluntarily participated in this study. A total of seven (7) female and one (1) male respondent were involved. In this study, only two respondents were homemakers, and the rest have formal works. They had various educational levels. It can be concluded that the level of education of each respondent provided an important background in terms of care, detection of early symptoms, treatment, and intervention. 
Table 1: Summary of Respondents' Demography

\begin{tabular}{cccclcc}
\hline $\begin{array}{c}\text { Respondent } \\
\text { (R) }\end{array}$ & Age & Gender & $\begin{array}{c}\text { Religion/ } \\
\text { Race }\end{array}$ & Occupation & Educational Level & $\begin{array}{c}\text { No. of } \\
\text { children }\end{array}$ \\
\hline R1 & 60 & Female & Islam/Malay & Homemaker & SPM & 1 \\
R2 & 45 & Female & Islam/Malay & Lecturer & Bachelor degree & 3 \\
R3 & 34 & Female & Islam/Malay & Lecturer & Bachelor degree & 3 \\
R4 & 43 & Male & Islam/Malay & Religious Officer Diploma & 3 \\
R5 & 39 & Female & Islam/Malay & Homemaker & Certificate & 3 \\
R6 & 38 & Female & Islam/Malay & Lecturer & Master degree & 1 \\
R7 & 49 & Female & Islam/Malay & Self-employed & PhD & 3 \\
R8 & 38 & Female & Islam/Malay & Teacher & Bachelor degree & 2 \\
\hline
\end{tabular}

Table 2: Summary of Children's Demography

\begin{tabular}{lcll}
\hline $\begin{array}{l}\text { Respondent } \\
\text { (R) }\end{array}$ & Age & Gender & Severity levels \\
\hline R1 & 21 & Male & Severe \\
R2 & 14 & Female & Mild \\
R3 & 6 & Male & Mild \\
R4 & 10 & Male & Moderate \\
R5 & 8 & Male & Moderate \\
R6 & 9 & Male & Moderate \\
R7 & 18 & Male & Moderate \\
R8 & 9 & Female & Mild \\
\hline
\end{tabular}

Theme 1: Challenges in Caregiving

There are four subthemes described by the respondents as the challenges in caregiving a child with autism. The subthemes are 1) emotional challenges, 2) physical challenges, 3 ) financial challenges, and 4) social life challenges.

\section{Emotional challenges}

The present study generally found that almost all study respondents went through emotional and financial burdens consistently in the process of caring for autistic children. But only a handful reported facing the burden on the aspects of social life where 'me time' or free time was quite limited. These findings are similar to the findings of Topan et al. (2019) whose respondents reported that they did not have time for themselves. This is different from what is reported and described as a relaxation time for caregivers of normal children. The first subtheme of emotions through the emotional response shown by the respondents in this study is seen the trend of almost all experiencing sadness and anger emotions in the context of care. However, the emotional effects experienced by some study respondents mostly focus on two or three emotions affected. Among the emotional responses were sadness, frustration, anger, and stress. All the responses faced were due to the perceptions and views of the surrounding individuals, the acceptance from family members, behaviour of the child, as well as personal satisfaction in childcare. A respondent said: 
"Sometimes it's sad when people say ... sometimes it's sadlah, yes we accept the situation he is in" (Respondent 5, Mrs. Zaiton)

"Hm, I'm sadlah, sometimes I'm sad aaa but once people understood, it's okaylah. This means that the process before he understands, there were some incidents that happened. So I feel frustrated/ah". (Respondent 6, Mrs. Syahirah)

\section{Physical Challenges}

Next on the physical subtheme, it can be reported that through the current researcher's interview with the study respondent, there were stressful situations and demanding instances where the caregiver needed to fulfill the child's demands. Most caregivers complained of fatigue and tiredness due to the continuous need to care for the child's behaviours. Fatigue is an inescapable state in the care of autistic children. The stress experienced by the caregiver was also through the endless presence of fatigue and its relationship with the caregiver's career. This study can also be compared with the study of Omaima Ezzat et al. (2017) whose respondents also reported experiencing physical subjective burdens such as fatigue, tiredness, and emotional turbulence. A respondent expressed that:

"Ha, that's right, sometimes, of course, sometimes when he behaves badly like that, sometimes we don't understand what he wants, right? Sometimes I feel so tired, God...I feel so so tired" (Respondent 5, Mrs. Zaiton).

Thus, the researchers found that all the respondents of the study experienced emotional and physical burdens as a result of childcare. These findings on burdens can be comparable to the study that has been done by Hasting (2002) and Isa et al. (2016). The burdens can be attributed to the process of handling the child's behaviour and fulfilling the child's demands by parents and guardians. The diversity of the child's spectrum and autistic behaviours presented different challenges for each caregiver. These emotional and physical caregiving burdens hae been proven to affect the caregivers, especially for formal careers. They need to keep up with working hours while at the same time, fulfill the child's needs. Therefore, it was inevitable that during certain times, they experienced a sense of helpless to handle a child. Researchers can apply the theory by Hans Selye (1979) where individuals go through a sense of inability to control something that happens. This occurs as a result of the interaction between emotional and physiological responses that affect the level of the individual's strength to cope with the pressures, challenges, and burdens. Thus, individuals who are able to rise again from that sense of inadequacy, unknowingly develop a mechanism against vulnerability within themselves to fight the obstacles, should these be present at other times in life.

\section{Financial Challenges}

The third subtheme is financial challenges. Caring for individuals with special needs costs money. Within this subtheme, the researchers found that several items contributed to the financial burden such as the management of daily expenses, food intake, therapy, and treatment care costs. Most of the study respondents in this study were middle-class citizens, with only two people were categorised as B40. Thus, financial issues can be identified to have a direct impact on all economic levels of caregivers whether the underprivileged or the middle class, working and unemployed. Some of the statements of respondents: 
"Then like he needed EIP of RM360 that we paid, then his therapy is different, we paid separately" (Respondent 5, Mrs. Zaiton)

Consequently, the financial needs are dependent on the needs of the children and the variety of needs (therapeutic needs, medical needs, learning needs, basic needs) described directly affecting the well-being of each caregiver. The results of this study support the finding of the study conducted by Misquiatti et al. (2015) where finances have an important impact on the care management of a child with disabilities. These are evidence from previous studies such as Oh, Kyoung, and Lee (2009); Misquiatti et al. (2015) found the significance of having adequate finance in the care of autistic children, as well as other disabled children. However, there were a few who states that the financial burden did not put pressure on the caregiver. This is due to the small number of children and sufficient income for childcare management. In this study, financial allocations were widely used for the purpose of child therapy, follow-up treatment, and motor-sensory therapy equipment. Some also reported the additional costs to provide comfort to the child and to meet the child's needs in terms of nutrition.

\section{Social Life Challenges}

The fourth subtheme, on social life also placed a burden on caregivers in the care management of autistic children. In this study, the researchers looked at the needs of caregivers to adapt to the conditions of working hours, the needs of their own time, and for social activities. Most of the respondents reported of not having their 'me time' enjoyed by most parents who had normal children. There were also respondents who reported that they did not have the freedom to go to supermarkets or shopping malls as they were always thinking about the condition of a child who cannot remain calm or can act dangerously. A respondent said:

"Haa so when I have a child like this, I can't do anything much, cannot hang out with people, haa then I have to take care of her... aarr so I am like I'm less social "(Respondent 8, Mrs. Sarah)

In this regard, on the allocation of time, some caregivers also stated that there was no problem with childcare management. This was due to the small number of children and the sociodemographic factors of caregivers who have flexible times due to being homemakers and self-employed. However, there are some findings of previous studies showed that almost all caregivers and mothers reported of not having their own free time and limited time for social activities (Dillenburger et al., 2010; Topen et al., 2019). With these various factors contributing to the burden, all factors can be balanced with adequate social factors especially in terms of support and assistance. In this study, it can also be concluded that in the financial subtheme there were two respondents getting financial aids from agencies and NGO such as JKM and NASOM. As for the social life theme, while the caregivers expressed dissatisfaction in social activities, researchers found that caregivers received ample positive support from various agencies in childcare. Thus, all sources of the challenges contribute to the hardship in care. It can be reduced through the adequacy of the supports obtained. The table below summarizes the findings: 
Table 3: Summary of Findings

Summary of findings:

1) Emotional challenges: sadness, anger, frustration, stress

2) Physical challenges: tiredness

3) Financial challenges: daily expenses, food intake, therapy/treatment

4) Social life challenges: social activity, freedom, relaxation time

\section{Theme 2: Coping Mechanisms}

In this theme, the researcher found that there were two important subthemes where these subthemes play a role in developing the high level of well-being among the caregivers. The subthemes are: 1 ) acceptance 2 ) spirituality

\section{Acceptance}

Findings show that acceptance was a very important aspect. This was because the caregivers would not be able to carry out the responsibilities in the care management of a special child perfectly if they as the caregivers were unable to fully accept the child's condition. If they accept their children's condition, indirectly they would be able to reduce the stress and burden they faced. Acceptance is very subjective and differs from one individual to another. Some only need a short time to accept certain fates or situations. There are also those who take a longer time to accept new situations and adapt their lives to new realities. Some respondents recounted:

"Haa that's it, but what to think, God has given us this, right? There must be blessings, right? Haa I am thankful, I never have regrets". (Respondent 1, Mrs. Siti)

"A lot, aaa when we already .. aaa what... we can already accept right. We felt easier than before umm... where sometimes we felt wanted to be angry." (Respondent 8, Mrs. Sarah)

In this study, each study respondent reported that the acceptance of the child's condition has led to higher overall well-being. All respondents reported that it was only in the early stages when they were informed of the child's condition, they were in shock. They faced difficult moments to accept the reality of the condition of the children they dreamt of being born normal and perfect. Most of the respondents reported that they went through an adjustment period of about 6 months after knowing the child's condition as the study of (Bilgin and Kucuk, 2010).

\section{Spirituality}

The spiritual aspect is related to the religious aspect and beliefs. This aspect became a positive source for every individual to hope, appeal, and express personal feelings. Prayers and supplications become a strength for the respondents in facing their difficult days. All the respondents studied were Muslims. Thus, they sought strength in religion through spiritual activities. Islam places great emphasis on the concept of contentment in receiving fates. Every human being is not free from the test to elevate him to a better and higher position as a servant of God. This belief and trust further facilitated the process of accepting and strengthens their trust in their struggle to help these children. Therefore, based on this study, the researchers found that all study respondents have high spiritual values which indirectly showed that they built self-satisfaction through positive and constructive thinkings. Acceptance and spiritual aspects have influenced the well-being of 
caregivers in the care of Autistic children. This is in line with the findings of Calistina Ubeh (2014); Ilias et al. (2017). At the level of acceptance, the caregiver accepted the fact that the child's condition cannot be changed but daily functioning can be improved. This belief served as a basis for the spirit for each caregiver to continue to support the child. Therefore, caregivers were prepared to experience fatigue, tiredness, and ready to accept the child's unpredictable development. Disappointment and acceptance will certainly be a frequent cycle for caregivers in managing and handling the special child.

\section{Conclusion}

Future studies need to explore and assess the issues of caregiver's well-being, quality of childcare, and quality of services that are yet to be answered. These issues need to be explored to ensure that caregivers of autistic children, especially, receive adequate assistance and support that are available in Malaysia. This study is expected to contribute to the field of developmental psychology, community health, and social work. The issue of accessibility of services for caregivers of autistic children and its difficulties among those with low incomes should continue to be focused on in future studies. Governmental agencies and NGOs also need to be more sensitive to this issue by further improving the quality and access of social work services to families with autistic children.

\section{Acknowledgements}

This research was supported by National University of Malaysia and the Ministry of Education Malaysia. The research code is SK-2020-022. Special thanks to the informants, experts and researchers who have participated in this research.

\section{References}

Aida, N., Adib, N., Ibrahim, M. I., Rahman, A. A., \& Bakar, R. S. (2019). Perceived Stress among Caregivers of Children with Autism Spectrum Disorder: A State-Wide Study. International Journal of Environment Research in Public Health, 16 (1468), 1-11. doi:10.3390/ijerph16081468

Aida, N., Adib, N., Ibrahim, M. I., Rahman, A. A., \& Bakar, R. S. (2019). Predictors of Caregivers ' Satisfaction with the Management of Children with Autism Spectrum Disorder : A Study at Multiple Levels of Health Care. International Journal of Environment Research in Public Health, 16 (1684), 1-18. doi:10.3390/ijerph16101684

Azizah, M. D., Jamal, A., \& Roslina, K. (2014). Kesejahteraan Hidup Subjektif: Pengaruh Elemen Ekonomi dan Bukan Ekonomi. Prosiding PERKEM ke-9, 719-727.

Bashir, A., Khurshid, S., \& Qadri, F. (2014). Awareness and Problems of Parents of Children with Autism Spectrum Disorders. International Journal of Interdisciplinary Research and Innovations, 2(2), 42-48.

Bilgin, H., Kucuk, L. (2010). Raising an autistic child: Perspectives from Turkish mothers. Journal of Child Adolescence Psychiatry Nursing, 23, 92-99.

Braun, V., \& Clarke, V. (2014). Successful Qualitative Research: A Practical Guide for Beginners. London: SAGE

Broady, R. T., Stoyles, G. J., \& Morse, C. (2018). Understanding carers' lived experience of stigma: The voice of families with a child on the autism spectrum. Health and Social Care in the Community, 25(1), 224-233. 
CDC (Centers for Disease Control and Prevention). (2010). Prevalence of autism spectrum disorder among children aged 8 years- autism and developmental disabilities monitoring network. Principal Investigators, 63(2), 1- 21.

Chan, K. K. S., \& Lam, C. B. (2017). Trait mindfulness attenuates the adverse psychological impact of stigma on parents of children with autism spectrum disorder. Mindfulness, 8, 984-994.

Cramm, J. M., \& Nieboer, A. P. (2011). Psychological well-being of caregivers of children with intellectual disabilities: Using parental stress as a mediating factor. Journal of Intellectual Disability, 15, 101-113.

Diener, E. (1984). Subjective well-being. Psychological Bulletin, 95, 542-575.

Diener, E., Diener, M., \& Diener, C. (1995). Factors predicting the subjective wellbeing of nations. Journal of Personality \& Social Psychology, 69(5), 851.

Dillenburger, K., Keenan, M., Doherty, A., Byrne, T., \& Gallagher, S. (2010). Living with children diagnosed with autism spectrum disorder: Parental and professional view. British Journal of Special Education, 37: 13-23.

Ezzat, O., Bayoumi, M., \& Samarkandi, O. A. (2017). Quality of Life and Subjective Burden on Family Caregiver of Children with Quality of Life and Subjective Burden on Family Caregiver of Children with Autism. American Journal of Nursing Science, 6(1), 33-39. doi: 10.11648/j.ajns.20170601.15

Goedeke, S., Shepherd, D., Landon, J., \& Taylor, S. (2019). How perceived support relates to child autism symptoms and care- related stress in parents caring for a child with autism. Research in Autism Spectrum Disorders, 60: 36-47.

Hastings, R. P. (2002). Parental stress and behaviour problems of children with developmental disability. Journal of Intellectual and Developmental Disability, 27: 149- 160.

Hoefman, R., Payakachat, N., Exel, J. V., Kuhlthau, K., Kovacs, E., Pyne, J., \& Tilford, J. M. (2014). Caring for a Child with Autism Spectrum Disorder and Parents' Quality of Life: Application of the CarerQol. Journal Autism Dev Disord, 44(8): 1933-1945. doi:10.1007/s10803-014-2066-1.

Ilias, K., Hui, J., Liaw, J., Cornish, K., Park, M. S., Golden, K. J., \& Ilias, K., (2017). Wellbeing of mothers of children with "A-U-T-I-S-M" in Malaysia: An interpretative phenomenological analysis study. Journal of Intellectual \& Developmental Disability, 42(1): 74-89. doi:10.3109/13668250.2016.1196657

Isa, S. N., Aziz, A. A., \& Rahman, A. A. (2013). The impact of disabled children on parent healthrelated quality of life and family functioning in Kelantan and its associated factors. Journal of Developmental and Behavioral Pediatrics, 34, 262- 268.

Karaarslan, Ö., \& Kutlu, M. (2015). Autism Spectrum Disorder Social Story in Individuals. Journal of Social Sciences Institute, 19: 1-17.

Kübler-Ross, E. (1969). On death and dying. New York: MacMillan

Landon, J., Shepherd, D., \& Goedeke, S. (2018). Predictors of Satisfaction with Life in Parents of Children with Autism Spectrum Disorder. Journal of Autism and Developmental Disorders, 48:1640-1650 https://doi.org/10.1007/s10803-017- 3423-7

Li, D., Larsen, L., Yang, Y., Wang, L., Zhai, Y., \& Sullivan, W. C. (2019). Exposure to nature for children with autism spectrum disorder: Benefits, caveats, and barriers. Health \& Place, 55: 71-79.

Lopez, K., Reed, J., \& Magaña, S. (2018). Children and Youth Services Review Associations among family burden, optimism, services received and unmet need within families of children with ASD. Children and Youth Services Review, 98: 105-112. 
MaHTAS (Malaysia Health Technology Assessment Section) (2014). Clinical Practice Guidelines. Management of Autism Spectrum Disorder in Children and Adolescents. https://www.moh.gov.my/moh/resources/maklumat\%20terkini/CPG_Mx_of_A SD_in_children_and_adolescents_draft.pdf

Misquiatti A. R. N., Brito, M. C., Ferreira, F. T. S., \& Junir, F. B. A. (2015). Family Burden and Children with Autism Spectrum Disorders: Perspective of Caregivers. Journal Family and Autism, 17(1):192-200.

Oh, H., Kyoung, E., \& Lee, O. (2009). Caregiver Burden and Social Support among Mothers Raising Children with Developmental Disabilities in South Korea. International Journal of Disability, Development and Education, 56 (2), 149-167, DOI:10.1080/10349120902868624

Othman, L. (2014). Penyelidikaan Kualitatif: Pengenalan Kepada Teori dan Metod. Tanjung Malim: UPSI Press.

Parameswari, S., \& Eljo, J. O. J. G. (2009). A Study on Psychological Well Being among the Parents of Children with Intellectual and Developmental Disabilities. Journal of Humanities and Social Science, 8-12

Jabatan Kebajikan Masyarakat. (2019). Perkhidmatan. Retrived from jkm.gov.my

Selye, H. (1976). Stress in health and disease. Reading, MA: Butterworth's.

Ting, Z., Yiting, W., \& Chunli, Y. (2018). Affiliate stigma and depression in caregivers of children with Autism Spectrum Disorders in China: Effects of self-esteem, shame and family functioning. Psychiatry Research, 264, 260-265

Topan, A., Demirel, S., Alkan, I., Ayyildiz, T. K., \& Dogru, S. (2019). Parenting an Autistic Child: A Qualitative Study. Int Arch Nurs Health Care, 5 (133): 1-7. doi.org/10.23937/2469$5823 / 1510133$

Ubeh C., Bahari F., \& Su Kiong P. V. (2017). Kesejahteraan Subjektif Ibu Bapa Kanak- Kanak Kurang Upayapembelajaran: Pengaruh Komitmen Keagamaan, Harapan Terhadap Anak, dan Sokongan Sosial Jurnal Psikologi Malaysia, 31(2): 45 - 56.

Wang, S. Y., Parrila, R., \& Cui, Y. (2013). Meta-analysis of social skills interventions of singlecase research for individuals with Autism Spectrum Disorders: Results from threelevel HLM. Journal of Autism and Developmental Disorders, 43: 1701- 1716

Werner, S., \& Shulman, C. (2013). Subjective well-being among family caregivers of individuals with developmental disabilities: The role of affiliate stigma and psychosocial moderating variables. Research in Developmental Disabilities, 34 (11): 4103-4114.

Wong, C. C. Y., Mak, W. W. S., \& Liao, K. Y. H. (2016). Self-compassion: A potential buffer against affiliate stigma experienced byparents of children with autism spectrum disorders. Mindfulness, 7, 1385-1395

Yamaoka, Y., Tamiya, N., Moriyama, Y., Garrido, S. F. A., Sumazaki, R., \& Noguchi, H. (2015). Mental Health of Parents as Caregivers of Childrenwith Disabilities: Based on Japanese Nationwide Survey. PLoS ONE 10 (12): e0145200. doi:10.1371/journal.pone.0145200 